Pacific Journal of Mathematics

ORTHOGONAL DEVELOPMENTS OF FUNCTIONALS AND
RELATED THEOREMS IN THE WIENER SPACE OF JAMES JUEI-CHIN YE H 


\section{ORTHOGONAL DEVELOPMENTS OF FUNCTIONALS AND RELATED THEOREMS IN THE WIENER SPACE OF FUNCTIONS OF TWO VARIABLES ${ }^{1}$}

\section{J. YEH}

1. Introduction. Let $C_{w}$ be the Wiener space of functions of two variables, i.e. the collection of real valued continuous functions $f(x, y)$ defined on $Q: 0 \leqq x, y \leqq 1$ and satisfying $f(0, y)=f(x, 0)=0$. Let $F[f]$ be a complex valued functional defined almost everywhere on $C_{w}$ and having Wiener measurable ${ }^{1}$ real and imaginary parts, and let $L_{2}\left(C_{w}\right)$ be the Hilbert space of functionals $F[f]$ satisfying

$$
\int_{\sigma_{w}}|F[f]|^{2} d_{w} f<\infty
$$

with the inner product

$$
\left(F_{1}, F_{2}\right)=\int_{\sigma_{w}} F_{1}[f] \overline{F_{2}[f]} d d_{w} f .
$$

The contents of this paper are:

1. An extension of the Cameron-Martin translation theorem, Theorem III, [11].

2. An extension of the Paley-Wiener theorem to $C_{w}$. Our proof is different from that of Paley and Wiener given for the Wiener space of functions of one variable and is based on the extended CameronMartin translation theorem, and

3. Construction of complete orthonormal systems in $L_{2}\left(C_{w}\right)$.

2. Theorem $\mathrm{I}^{2}$. Let $p(x, y)$ be of bounded variation ${ }^{3}$ on $Q, p(0, y)$, $p(1, y), p(x, 0), p(x, 1)$ be of bounded variation on the respective unit interval. Let $p(x, y)$ be continuous a.e. and bounded on $Q$. Let

$$
\begin{aligned}
& q(x, y)=\int_{Q_{x y}} p(s, t) d s d t \text { where } Q_{x y}=[0, x] \times[0, y] \\
& 0 \leqq x, y \leqq 1
\end{aligned}
$$

Let $I^{\prime} \subset C_{w}$ be Wiener measurable and a translation $T$ be defined by

Received January 29, 1963. This research was partially supported by the Mathematics Division of the Air Force Office of Scientific Research under Contract No. AF 49 (638)1046. The author is indebted to [2] in the writing of this article.

${ }_{1}^{1}$ For the definition of the Wiener measure and Wiener measurable functionals, see [10] or [11].

2 Theorem 1 can also be derived from Theorem 3, [9].

${ }^{3}$ For functions of bounded variation in $n$ variables and Riemann-Stieltjes integrals with respect to them, see $[\mathbf{1 1}]$. 


$$
T \Gamma=\left\{f \in C_{w} ; f=g-q, g \in \Gamma\right\} \text {. }
$$

Then

$$
m(\Gamma)=\exp \left\{-\int_{Q} p^{2} d x d y\right\} \int_{T T^{\prime}} \exp \left\{-2 \int_{Q} p d^{2} f\right\} d_{w} f
$$

and if $F[g]$ is a real valued measurable functional defined on ${ }^{\prime}$,

$$
\begin{aligned}
\int_{\Gamma} F[g] d_{w} g= & \exp \left\{-\left\{p_{Q} p^{2} d x d y\right\} \int_{T \Gamma} F[f+q]\right. \\
& \exp \left\{-2 \int_{Q} p d^{2} f\right\} d_{w} f .
\end{aligned}
$$

The proof of this theorem for the most part consists in justification for passing to the limit under the various integral signs involved and is lengthy and we shall only give an outline in the following leaving the details to the reader.

The linearization $L_{p}$ of a function $p(x, y)$ defined on $Q$ corresponding to a partition $\mathfrak{P}_{\beta}$ of $Q: 0=x_{0}<x_{1}<\cdots<x_{m}=1,0=y_{0}<y_{1}<\cdots<y_{n}=1$ is the continuous function defined on $Q$ which agrees with $p(x, y)$ at $\left(x_{i}, y_{j}\right), i=0,1,2, \cdots, m ; j=0,1,2, \cdots, n$ and is linear on each of the $2 m n$ closed rectangular triangles having either $\left(x_{i-1}, y_{j-1}\right),\left(x_{i}, y_{j-1}\right)$, $\left(x_{i}, y_{j}\right)$ or $\left(x_{i-1}, y_{j-1}\right),\left(x_{i-1}, y_{j}\right),\left(x_{i}, y_{j}\right)$ as corners.

The following theorem can be proved more or less in the same way Helly's 2nd theorem is proved.

THEOREM. Let $p(x, y) \in B . V .(Q)$ and let $\left\{\mathfrak{P}_{k}\right\}$ be a sequence of partitions of $Q$ such that

$1^{\circ} \lim _{k \rightarrow \infty} \sum_{i} \sum_{j}\left|p\left(x_{i}^{(k)}, y_{j}^{(k)}\right)-p\left(x_{i}^{(k)}, y_{j-1}^{(k)}\right)-p\left(x_{i-1}^{(k)}, y_{j}^{(k)}\right)+p\left(x_{i-1}^{(k)}, y_{j-1}^{(k)}\right)\right|=0$

$2^{\circ}$ each $\mathfrak{\Re}_{k}$ is a refinement of its predecessor and $\lim _{k \rightarrow \infty}\left|\mathfrak{F}_{k}\right|=0$

where $\left|\mathfrak{P}_{k}\right|=\max _{i j}\left\{\left|x_{i}-x_{i-1}\right|,\left|y_{j}-y_{j-1}\right|\right\}$, and let $\left\{L_{k} p\right\}$ be the sequence of linearizations of $p$ corresponding to $\left\{\mathfrak{P}_{k}\right\}$. Let $\left\{f_{k}(x, y)\right\}$ be a sequence of continuous functions which converges uniformly to $f(x, y)$ on $Q$. Then

$$
\lim _{k \rightarrow \infty} \int_{Q} f_{k}(x, y) d^{2} L^{k} p(x, y)=\int_{Q} f(x, y) d^{2} p(x, y) .
$$

Now let

$$
q_{k}(x, y)=\int_{Q_{x y}} L_{k} p(s, t) d s d t
$$

Theorem II, [11] holds with $q_{k}$ replacing $f_{0}$ since $q_{k}$ satisfies the con- 
ditions on $f_{0}$. Letting $k \rightarrow \infty$ and justifying passing to the limit under the integral signs by bounded convergence and utilizing our theorem above, we derive Theorem I the way Theorem III, |11| was derived from Theorem II, [11].

CoRollary. If p satisfies the conditions of Theorem I, then for every complex number $\lambda$

$$
\int_{a_{w}} \exp \left\{\lambda \int_{Q} p d^{2} f\right\} d_{w} f=\exp \left\{\frac{\lambda^{2}}{4}\left\{p_{Q} p^{2} d x d y\right\} .\right.
$$

Proof. Let a translation $T$ be defined by (2.2). Then $T C_{w}=C_{w}$. Since $m\left(C_{w}\right)=1,(2.3)$ reduces to

$$
1=\exp \left\{-\int_{Q} p^{2} d x d y\right\} \int_{\sigma_{w}} \exp \left\{-2 \int_{Q} p d^{2} f\right\} d_{w} f .
$$

Let $\lambda$ be a real number. If we replace $p$ by $-(\lambda / 2) p$ which satisfies the conditions on $p,(2.6)$ becomes (2.5), and (2.5) holds for real $\lambda$.

Now let $\lambda \in C$, the complex plane. The right hand side (2.5) is a holomorphic function on $C$. According to the identity theorem of holomorphic functions, to prove (2.5) we only have to show that the left hand is also holomorphic on $C$. This is done by means of Morera's theorem.

Let $I^{\prime}$ be a smooth contour in $C$ and parametrize it by its arc length $s, 0 \leqq s \leqq 1$ so that $\left|\lambda^{\prime}(s)\right|=1$. Consider

$$
\begin{aligned}
\int_{l}\left[\int_{\sigma_{w}} \exp \right. & \left.\left\{\lambda \int_{Q} p d^{3} f\right\} d d_{w} f\right] d \lambda \\
= & \int_{0}^{l}\left[\int_{\sigma_{w}} \exp \left\{\lambda(s) \int_{Q} p d^{2} f\right\} \lambda^{\prime}(s) d_{w} f\right] d s .
\end{aligned}
$$

To apply Fubini's theorem, we show that the iterated integrals of the absolute values of the real and imaginary parts of the integrand are finite. Let $\lambda_{0}$ be a real number such that $|\lambda| \leqq \lambda_{0}$ for $\lambda \in \Gamma$. For any real $u,\left|e^{\lambda u}\right|<e^{\lambda_{0} u}+e^{-\lambda_{0} u}$ when $\lambda \in \Gamma$ and hence

$$
\begin{aligned}
& \int_{0}^{\iota}\left[\int_{\sigma_{w}} \mid \operatorname{Re} \exp \left\{\lambda(s) \int_{Q} p d^{2} f^{\prime} \lambda^{\prime}(s) \mid d_{w} f\right] d s\right. \\
& \leqq \int_{0}^{l}\left[\int_{\sigma_{w}}\left\{\exp \left\{\lambda_{0} \int_{Q} p d^{\prime \prime} f^{\}}+\exp \left\{-\lambda_{11} \int_{Q} p d^{\prime \prime} f\right\}\right\} d d_{m} f\right] d s\right. \\
& =2 l \exp \left\{\frac{\lambda_{0}^{2}}{4} \int_{Q} p^{2} d x d y\right\}
\end{aligned}
$$

which is finite. The same argument goes for the imaginary part. Thus by Fubini's theorem 


$$
\begin{aligned}
& \int_{0}^{l}\left[\int_{\sigma_{w}} \exp \left\{\lambda(s) \int_{Q} p d^{2} f\right\} \lambda^{\prime}(s) d_{w} f\right] d s \\
& \quad=\int_{\sigma_{w}}\left[\int_{I^{\prime}} \exp \left\{\lambda \int_{Q} p d^{2} f\right\} d \lambda\right] d_{w} f=\int 0 d_{w} f=0
\end{aligned}
$$

because $\exp \left\{\lambda \int_{Q} p d^{2} f\right\}$ is holomorphic on $C$. Thus by Morera's theorem, the left hand side (2.5) is holomorphic on $C$ and (2.5) holds.

3. THEOREM II. Let $\left\{p_{j}(x, y)\right\}, j=1,2, \cdots, n$ be an orthonormal set of functions on $Q$ with each $p_{j}$ satisfying the condition on $p$ in Theorem 1. If $\Phi\left(u_{1}, \cdots, u_{n}\right)$ is a complex valued Lebesgue measurable function on $R_{n}$, the functional

$$
F[f]=\Phi\left[\int_{Q} p_{1} d^{2} f, \cdots, \int_{Q} p_{n} d^{2} f\right]
$$

is Wiener measurable on $C_{w}$ and

$$
\begin{aligned}
& \int_{\sigma_{w}} F[f] d_{w} f \\
& \quad=\pi^{-n / 2} \int_{-\infty}^{\infty}(n) \int_{-\infty}^{\infty} \Phi\left(u_{1}, \cdots, u_{n}\right) \exp \left\{-\sum_{j=1}^{n} u_{j}^{2}\right\} d u_{1} \cdots d u_{n}
\end{aligned}
$$

in the sense that the existence of one side implies that of the other together with the equality.

REMARK. Let $-\infty<\alpha<\beta<\infty$ and let $k$ be so large that $\alpha+(1 / k)<\beta$. Let $\Phi_{\alpha \beta k}(u)$ be the trapezoidal function defined by

$$
\Phi_{\alpha \beta k}(u)=\left[\begin{array}{ll}
0 & u \leqq \alpha \\
k(u-\alpha) & \alpha \leqq u \leqq \alpha+\frac{1}{k} \\
1 & \alpha+\frac{1}{k} \leqq u \leqq \beta \\
-k(u-\beta)+1 & \beta \leqq u \leqq \beta+\frac{1}{k} \\
0 & \beta+\frac{1}{k} \leqq u .
\end{array}\right.
$$

Then

(3.4) $\Phi_{\alpha \beta k}(u)=\frac{k}{2 \pi} \int_{-\infty}^{\infty} \frac{e^{i u v}}{v^{2}}\left\{-e^{-i \alpha v}+e^{-i[\alpha+(1 / k)] v}+e^{-i \beta v}-e^{-i[\beta+(1 / k)] v}\right\} d v$.

This follows immediately from the following result in the calculus of residues: 


$$
\int_{-\infty}^{\infty} \frac{e^{i \alpha z}}{z^{2}} d z=\left[\begin{array}{ll}
-2 \pi \alpha & \alpha \geqq 0 \\
0 & \alpha \leqq 0
\end{array}\right.
$$

where the left hand side stands for the limit as $R \uparrow \infty, \delta \downarrow 0$ of the integral of the same integrand along $\Gamma_{R \delta}$ on the $z$-plane defined by

$$
\Gamma_{R \delta}=\{z|\delta \leqq| x \mid \leqq R, y=0\} \cup\{z|| z \mid=\delta, y \leqq 0\} .
$$

Proof of Theorem II. (1) Consider the Lebesgue measurable function defined on $R_{n}$.

$$
\Phi\left(u_{1}, \cdots, u_{n}\right)=\exp \left\{i \sum_{j=1}^{n} \lambda_{j} u_{j}\right\}, \quad \lambda_{j}, \quad \text { real }
$$

and the corresponding functional defined by (3.1)

$$
F[f]=\exp \left\{i \sum_{j=1}^{n} \lambda_{j} \int_{Q} p_{j} d^{2} f\right\} .
$$

To show that $F[f]$ is Wiener measurable on $C_{w}$ it suffices to show that $\int_{Q} p_{j} d^{2} f$ is for each $j$. Now since $\int_{Q} p_{j} d^{2} f$ exists for all $f \in C_{w}$, let us choose independently of $f$ a sequence of partitions $\left\{\mathfrak{P}_{k}\right\}$ of $Q$ with $\lim _{k \rightarrow \infty}\left|\mathfrak{P}_{k}\right|=0$. For definiteness we may also agree to choose $\left(\xi_{i}^{(k)}, \eta_{j}^{(k)}\right), i=1,2, \cdots, m(k), j=1,2, \cdots, n(k)$ in the Riemann-Stieltjes sum to be always $\left(x_{i}^{(k)}, y_{j}^{(k)}\right)$.

Since $\sum_{r=1}^{n} \lambda_{j} p_{j}$ satisfies the condition on $p$ of the Corollary of Theorem I, $\S 2$, we have, by the orthonormality of $\left\{p_{j}\right\}$

$$
\begin{aligned}
\int_{c_{w}} F[f] d_{w} f & =\int_{\sigma_{w}} \exp \left\{i \sum_{j=1}^{n} \lambda_{j} \int_{Q} p_{j} d^{2} f\right\} \\
& =\exp \left\{-\frac{1}{4} \int_{Q}\left\{\sum_{j=1}^{n} \lambda_{j} p_{j}\right\}^{2} d x d y\right\}=\exp \left\{-\frac{1}{4} \sum_{j=1}^{n} \lambda_{j}^{2}\right\} .
\end{aligned}
$$

On the other hand

$$
\begin{aligned}
& \pi^{-n / 2} \int_{-\infty}^{\infty}(n) \int_{-\infty}^{\infty} \Phi\left(u_{1}, \cdots, v_{n}\right) \exp \left\{-\sum_{j=1}^{n} u_{j}^{2}\right\} d u_{1} \cdots d u_{n} \\
& \quad=\pi^{-n / 2} \int_{-\infty}^{\infty}(n) \int_{-\infty}^{\infty} \exp \left\{i \sum_{j=1}^{i} \lambda_{j} u_{j}\right\} \exp \left\{-\sum_{j=1}^{n} u_{j}^{2}\right\} d u_{1} \cdots d u_{n} \\
& \quad=\pi^{-n / 2} \prod_{j=1}^{n} \int_{-\infty}^{\infty} \exp \left\{i \lambda_{j} u_{j}-u_{j}^{2}\right\} d u_{j} \\
& \quad=\pi^{-n / 2} \prod_{j=1}^{n} \int_{-\infty}^{\infty} \exp \left\{-\left(u_{j}-\frac{i \lambda_{j}}{2}\right)^{2}\right\} d\left(u_{j}-\frac{i \lambda_{j}}{2}\right) \exp \left\{-\frac{\lambda_{j}^{2}}{4}\right\} \\
& \quad=\exp \left\{-\frac{1}{4} \sum_{j=1}^{n} \lambda_{j}^{2}\right\} .
\end{aligned}
$$

Thus both sides of (3.2) exist and (3.2) holds. 
(2) Let $\Phi\left(u_{1}, \cdots, u_{n}\right)$ be the characteristic function $\chi_{I}\left(u_{1}, \cdots, u_{n}\right)$ of an interval $I$ in $R_{n}$, i.e. let

$$
\begin{aligned}
I=I_{1} \times \cdots \times I_{n} \text { with } I_{j} & =\left\{u_{j} \in R_{1} ;-\infty \leqq \alpha_{j}<u_{j} \leqq \beta_{j} \leqq \infty\right\}, \\
j & =1,2, \cdots, n .
\end{aligned}
$$

Consider the case where $I$ is bounded, i.e. $-\infty \leqq \alpha_{j}, \beta_{j} \leqq \infty, j=$ $1,2, \cdots, n$. Now

$$
\begin{aligned}
\Phi\left(u_{1}, \cdots, u_{n}\right)= & \chi_{I}\left(u_{1}, \cdots, u_{n}\right)=\prod_{j=1}^{n} \Phi_{j}\left(u_{j}\right) \\
& \text { with } \Phi\left(u_{j}\right)=\chi_{I_{j}}\left(u_{j}\right), j=1,2, \cdots, n .
\end{aligned}
$$

Let $\Phi_{j, k}\left(u_{j}\right)=\Phi_{\alpha_{j} \beta_{j, k}}\left(u_{j}\right)$ as defined in Remark and let

$$
\begin{aligned}
\Phi_{k}\left(u_{1}, \cdots, u_{n}\right) & =\prod_{j=1}^{n} \Phi_{j, k}\left(u_{j}\right), \\
F_{k}[f] & =\Phi_{k}\left[\int_{Q} p_{1} d^{2} f, \cdots, \int_{Q} p_{n} d^{2} f\right], \\
F[f] & =\Phi\left[\int_{Q} p_{1} d^{2} f, \cdots, \int_{Q} p_{n} d^{2} f\right] .
\end{aligned}
$$

The functionals $F_{k}[f], F[f]$ are Wiener measurable. Now by Remark

$$
\begin{aligned}
& \int_{\sigma_{w}} F_{k}[f] d_{w} f=\int_{\sigma_{w}} \prod_{j=1}^{n} \Phi_{j_{k}}\left[\int_{Q} p_{j} d^{2} f\right] d_{w} f \\
& \quad=\int_{\sigma_{w}} \frac{k^{n}}{(2 \pi)^{n}}\left[\int_{-\infty}^{\infty}(n) \int_{-\infty}^{\infty} \exp \left\{i \sum_{j=1}^{n} v_{j} \int_{Q} p_{j} d^{2} f\right\} \prod_{j=1}^{n} \Psi_{j, k}\left(v_{j}\right) d v_{1} \cdots d v_{n}\right]
\end{aligned}
$$

where

$$
\begin{aligned}
\Psi_{j, k}\left(v_{j}\right)= & \frac{1}{v_{j}^{2}}\left[-\exp \left\{-i \alpha_{j} v_{j}\right\}+\exp \left\{-i\left(\alpha_{j}+\frac{1}{k}\right) v_{j}\right\}\right. \\
& \left.+\exp \left\{-i \beta_{j} v_{j}\right\}-\exp \left\{-i\left(\beta_{j}+\frac{1}{k}\right) v_{j}\right\}\right]
\end{aligned}
$$

Now since

$$
\left|\exp \left\{i \sum_{j=1}^{n} v_{j} \int_{Q} p_{j} d^{2} f\right\} \prod_{j=1}^{n} \Psi_{j, k}\left(u_{j}\right)\right| \leqq \prod_{j=1}^{n}\left|\Psi_{j, k}\left(u_{j}\right)\right| \leqq 4^{n} \prod_{j=1}^{n} \frac{1}{v_{j}^{2}}
$$

so that the repeated integral of the absolute value of the integrand is finite and Fubini's theorem is applicable. Thus 


$$
\begin{aligned}
\int_{\sigma_{w}} F_{k}[f] d_{w} f \\
=\int_{-\infty}^{\infty}(n) \int_{-\infty}^{\infty} \frac{k k^{n}}{(2 \pi)^{n}}\left[\int_{\sigma_{w}} \exp \left\{i \sum_{j=1}^{n} v_{j} \int_{Q} p_{j} d^{2} f\right\} d_{w} f\right] \prod_{j=1}^{n} \Psi_{j k}\left(v_{j}\right) d v_{1} \cdots d v_{n} \\
=\int_{-\infty}^{\infty}(n) \int_{-\infty}^{\infty} \frac{k k^{n}}{(2 \pi)^{n}}\left[\pi^{-n / 2} \int_{-\infty}^{\infty}(n) \int_{-\infty}^{\infty} \exp \left\{i \sum_{j=1}^{n} u_{j} v_{j}\right\} \exp \left\{-\sum_{j=1}^{n} u_{j}^{2}\right\}\right. \\
\left.\quad \cdot \prod_{j=1}^{n} \Psi_{j, k}\left(v_{j}\right) d u_{1} \cdots d u_{n}\right]
\end{aligned}
$$

where the second equality is from (1). Applying Fubini's theorem again

$$
\begin{aligned}
\int_{c_{w}} F_{k} & {[f] d d_{w} f=\int_{-\infty}^{\infty}(n) \int_{-\infty}^{\infty} \pi^{-n / 2} \prod_{j=1}^{n} } \\
& \cdot\left[\frac{k}{2 \pi} \int_{-\infty}^{\infty} \exp \left\{i u_{j} v_{j}\right\} \Psi_{j, k}\left(v_{j}\right) d v_{j}\right] \exp \left\{-\sum_{j=1}^{n} u_{j}^{2}\right\} d u_{1} \cdots d u_{n} \\
= & \pi^{-n / 2} \int_{-\infty}^{\infty}(n) \int_{-\infty}^{\infty} \prod_{j=1}^{n} \Phi_{j k}\left(u_{j}\right) \exp \left\{-\sum_{j=1}^{n} u_{j}^{2}\right\} d u_{1} \cdots d u_{n} \\
= & \pi^{-n / 2} \int_{-\infty}^{\infty}(n) \int_{-\infty}^{\infty} \Phi_{k}\left(u_{1}, \cdots, u_{n}\right) \exp \left\{-\sum_{j=1}^{n} u_{j}^{2}\right\} d u_{1} \cdots d u_{n} .
\end{aligned}
$$

Since $F_{k}[f]$ and $\Phi_{k}\left(u_{1}, \cdots, u_{n}\right)$ converge nondecreasingly to $F[f]$ and $\Phi\left(u_{1}, \cdots, u_{n}\right)$ respectively, both sides of (3.2) exist and (3.2) holds if we let $k \rightarrow \infty$ in the last equality according to Levi's monotone convergence theorem.

When $I$ is unbounded, we take an increasing sequence of bounded intervals $\left\{I_{r}\right\}$ which converges to $I$. Then $\chi_{I_{r}}\left(u_{1}, \cdots, u_{n}\right) \uparrow \chi_{I}\left(u_{1}, \cdots, u_{n}\right)$ as $r \rightarrow \infty$ on $R_{n}$ and hence $\chi_{I_{r}}[f] \uparrow \chi_{I}[f]$ as $r \rightarrow \infty$ on $C_{w}$. Thus $\chi_{I}[f]$ is Wiener measurable. For each $\chi_{I_{r}}\left(u_{1}, \cdots, u_{n}\right)$, both sides of (3.2) exist and (3.2) holds. By Levi's monotone convergence theorem, the same is true of $\chi_{I}\left(u_{1}, \cdots, u_{n}\right)$.

(3) To complete the proof of the theorem we show that both sides of (3.2) exist and are equal when $\Phi$ is the characteristic function of an 0 -set, an $0_{\delta}$-set (i.e. the intersection of countably many 0 -sets), a null set and finally a measurable set in $R_{n}$. We then show that the same is true when $\Phi$ is an integrable simple function and when it is an extended positive valued measurable function defined on $R_{n}$. We conclude by showing that when $\Phi$ is an extended real valued or a complex valued measurable function on $R_{n}$ the existence of one side of (3.2) implies that of the other and the equality of the two. 


$$
\int_{\sigma_{w}}\left[\int_{Q} p d^{2} f\right]^{2} d_{w} f=\frac{1}{2} \int_{Q} p^{2} d x d y
$$

Proof. In case $\int_{Q} p^{2} d x d y=0, p(x, y)=0$ a.e. on $Q, \int_{Q} p d^{2} f=0$ for all $\mathrm{f} \in C_{w}$, and hence $\int_{\sigma_{w}}\left[\int_{Q} p d^{2} f\right]^{2} d_{w} f=0$ and the corollary holds trivially.

Suppose $\int_{Q} p^{2} d x d y \neq 0$. Let $\varphi(x, y)=(1 / \lambda) p(x, y)$ where $\lambda=$ $\left\{\int_{Q} p^{2} d x d y\right\}^{1 / 2} \cdot \stackrel{Q_{Q}}{\text { By }}$ Theorem II

$$
\begin{aligned}
\int_{\sigma_{w}}\left[\int_{Q} p d^{2} f\right] d d_{w} f & =\lambda^{2} \int_{\sigma_{w}}\left[\int_{Q} \varphi d^{2} f\right]^{2} d_{w} f \\
& =\lambda^{2} \frac{1}{\sqrt{\pi}} \int_{-\infty}^{\infty} u^{2} e^{-u^{2}} d u=\frac{\lambda^{2}}{2}=\frac{1}{2} \int_{Q} p^{2} d x d y
\end{aligned}
$$

4. Definition 1. Let $\left\{e_{m}(u)\right\}, m=0,1,2, \cdots$, be a C.O.N. system in the separable Hilbert space $L_{2}(-\infty, \infty)$ with

$$
e_{0}(u)=\pi^{-1 / 4} \exp \left\{-\frac{u^{2}}{2}\right\}
$$

and let

$$
G_{m}(u)=\pi^{1 / 4} \exp \left\{\frac{u^{2}}{2}\right\} e_{m}(u), \quad m=0,1,2, \cdots
$$

As immediate consequences of the definition, we have

$$
\begin{gathered}
G_{0}(u) \equiv 1 \\
\pi^{-1 / 2} \int_{-\infty}^{\infty} G_{m}(u) G_{n}(u) \exp \left\{-u^{2}\right\} d u=\delta_{m n} \\
\pi^{-1 / 2} \int_{-\infty}^{\infty} G_{m}(u) \exp \left\{-u^{2}\right\} d u=0, \quad m=1,2, \cdots .
\end{gathered}
$$

As an example of $G_{m}(u)$, let us name the partially normalized. Hermite polynomials

$$
G_{m}(u)=(-1)^{m} 2^{-m / 2}(m !)^{-1 / 2} \exp \left\{u^{2}\right\} \frac{d^{m}}{d u^{m}} \exp \left\{-u^{2}\right\}, \quad m=0,1,2, \cdots
$$

Definition 2. Let $\left\{p_{k}(x, y)\right\}$ be a C.O.N. system of real valued: functions in $L_{2}(Q)$ with each $p_{k}$ satisfying the conditions on $p$ in. Theorem I. Let

$$
\Phi_{m k}[f]=G_{m}\left[\int_{Q} p_{k} d^{2} f\right], \quad \text { for } f \in C_{w}
$$




$$
\Psi_{m_{1}, \ldots, m_{r}}[f]=\Phi_{m_{1}, 1}[f] \cdots \Phi_{m_{r}, r}[f] .
$$

Then by (4.3)

$$
\begin{aligned}
\Phi_{0 k}[f] & =1 \\
\Psi_{m_{1}, \ldots, m_{r}, 0, \ldots, 0}[f] & =\Psi_{m_{1}, \ldots, m_{r}}[f] .
\end{aligned}
$$

Definition 3. Let $\left\{\Psi_{\alpha}\right\}$ be the collection of the functionals of the form (4.7), i.e. $\alpha \in A$, which is the collection of sequences of natural numbers with finitely many nonzero entries.

THEOREM III. The series expansion of any $F[f] \in L_{2}\left(C_{w}\right)$ in $\left\{\Psi_{\alpha}\right\}$ converges to $F[f]$ in the $L_{2}\left(C_{w}\right)$ sense, i.e.

$$
\lim _{N \rightarrow \infty} \int_{\sigma_{w}}\left|F[f]-\sum_{m_{1}} \sum_{, m_{N}=0}^{N} A_{m_{1}, \ldots, m_{N}} \Psi_{m_{1}, \ldots, m_{N}}[f]\right|^{2} d_{w} f=0
$$

where $A_{m_{1}, \ldots, m_{N}}$ are the Fourier coefficients

$$
A_{m_{1} \cdots m_{N}}=\int_{\sigma_{w}} F[f] \Psi_{m_{1}, \cdots, m_{N}}[f] d_{w} f .
$$

The proof is based on the following lemmas.

LeMma 1. $\left\{\Psi_{\alpha}\right\}$, is a O.N. system over $C_{w}$.

Corollary. The Bessel inequality and the best approximation theorem hold with $\left\{\Psi_{\alpha}\right\}$.

Definition 5. We say that $F[f] \in S_{n}\left\{p_{k}\right\}$ if $F[f]$ is defined on $C_{w}$ and

$$
F[f]=\Phi\left[\int_{Q} p_{1} d^{2} f, \cdots, \int_{Q} p_{n} d^{2} f\right]
$$

where

$$
\Phi\left(u_{1}, \cdots, u_{n}\right) \exp \left\{-\frac{1}{2}\left(u_{1}^{2}+\cdots+u_{n}^{2}\right)\right\} \in L_{2}\left(R_{n}\right)
$$

LeMma 2. Let $F[f] \in S_{n}\left\{p_{k}\right\}$, then with $m_{r} \neq 0$,

$$
\int_{\sigma_{w}} F[f] \Psi_{m_{1}, \cdots, m_{r}}[f] d_{w} f= \begin{cases}0 & \text { if } r \neq n \\ \varphi_{m_{1} \cdots m_{n}} & \text { if } r=n\end{cases}
$$

where 


$$
\begin{aligned}
\varphi_{m_{1}, \cdots, m_{n}}= & \pi^{-n / 2} \int_{-\infty}^{\infty}(n) \int_{-\infty}^{\infty} \Phi\left(u_{1}, \cdots, u_{n}\right) \\
& \cdot \exp \left\{-\sum_{k=1}^{n} u_{k}^{2}\right\}\left\{\sum_{k=1}^{n} G_{m_{k}}\left(u_{k}\right)\right\} d u_{1} \cdots d u_{n} .
\end{aligned}
$$

LEMma 3. If $F[f] \in S_{n}\left\{p_{k}\right\}$ for some $n$, the orthogonal development of $F[f]$ in $\left\{\Psi_{a}\right\}$ converges in the $L_{2}\left(C_{w}\right)$ sense to $F[f]$.

LEMma 4. Functionals of the type given in Definition 5 are dense in $L_{2}\left(C_{w}\right)$ in the sense of Hilbert metric, i.e. if $F[f] \in L_{2}\left(C_{w}\right)$, for every $\varepsilon>0$ there exists a positive integer $l$ and a functional $F^{*}[f] \in S_{l}\left\{p_{\lambda}\right\}$ such that

$$
\left\{\int_{c_{w}}\left|F[f]-F^{*}[f]\right|^{2} d_{w} f\right\}^{1 / 2}<\varepsilon .
$$

These lemmas are proved by means of Theorem II in the same way the corresponding lemmas for the Wiener space of functions of one variable are proved in [4] with relevant modifications made for the two variable case. We wish to point out that in the proofs in [4] only those properties of partially normalized Hermite polynomials that are our (4.2), (4.3), (4.4), (4.5) are utilized.

\section{BIBLIOGRAPHY}

1. N. I. Achieser and I. M. Glasmann, Theorie der linearen Operatoren im Hilbert-Raum, Akademie Verlag, Berlin, 1960.

2. R. H. Cameron, Integration in Function Spaces, Unpublished lecture notes.

3. R. H. Cameron and W. T. Martin, Transformation of Wiener integrals under translations, Annals of Math., 45 (1944), 386-396.

4. - The orthogonal develspment of non-linear functionals in series of FourierHermite functionals, Annals of Math., 48 (1944), 385-392.

5. R. Courant and D. Hilbert, Methoden der mathematischen Physik, Bd. I., Verlag von Julius Springer, Berlin, 1931.

6. A. Haar, Zur Theorie der orthogonalen Funktionensysteme, Mathematische Annalen, Bd. 69 (1910), 331-371.

7. R. E. A. C. Paley and N. Wiener, Fourier transforms in the complex domain, Amer. Math. Soc. Coll. Pub., Vol. XIX, New York, 1934.

8. - and A. Zygmund, Notes on random functions, Mathematische Zeitschrift, Bd. 37 (1933), 647-668.

9. I. E. Segal, Distributions in Hilbert space and canonical systems of operators, Trans. Amer. Math. Soc., 88 (1958), 12-41.

10. J. Yeh, Wiener measure in a space of functions of two variables, Trans, Amer. Math. Soc., 95 (1960), 443-450.

11. - Cameron-Martin translation theorems in the Wiener space of functions of two variables, To appear in Trans. Amer. Math. Soc.

UNIVERSITY OF ROCHESTER 


\section{PACIFIC JOURNAL OF MATHEMATICS}

\section{EDITORS}

RalPh S. Phillips

Stanford University

Stanford, California

M. G. Arsove

University of Washington

Seattle 5 , Washington
J. Dugundu

University of Southern California

Los Angeles 7, California

Lowell J. Paige

University of California

Los Angeles 24, California

\section{ASSOCIATE EDITORS}
E. F. BECKENBACH
D. DERRY
H. L. ROYDEN
E. G. STRAUS
T. M. CHERRY
M. OHTSUKA
E. SPANIER
F. WOLF

\section{SUPPORTING INSTITUTIONS}

\author{
UNIVERSITY OF BRITISH COLUMBIA \\ CALIFORNIA INSTITUTE OF TECHNOLOGY \\ UNIVERSITY OF CALIFORNIA \\ MONTANA STATE UNIVERSITY \\ UNIVERSITY OF NEVADA \\ NEW MEXICO STATE UNIVERSITY \\ OREGON STATE UNIVERSITY \\ UNIVERSITY OF OREGON \\ OSAKA UNIVERSITY \\ UNIVERSITY OF SOUTHERN CALIFORNIA
}

\author{
STANFORD UNIVERSITY \\ UNIVERSITY OF TOKYO \\ UNIVERSITY OF UTAH \\ WASHINGTON STATE UNIVERSITY \\ UNIVERSITY OF WASHINGTON \\ AMERICAN MATHEMATICAL SOCIETY \\ CALIFORNIA RESEARCH CORPORATION \\ SPACE TECHNOLOGY LABORATORIES \\ NAVAL ORDNANCE TEST STATION
}

Mathematical papers intended for publication in the Pacific Journal of Mathematrcs should be typewritten (double spaced), and the author should keep a complete copy. Manuscripts may be sent to any one of the four editors. All other communications to the editors should be addressed to the managing editor, L. J. Paige at the University of California, Los Angeles 24, California.

50 reprints per author of each article are furnished free of charge; additional copses may be obtained at cost in multiples of 50 .

The Pacific Journal of Mathematics is published quarterly, in March, June, September, and December. Effective with Volume 13 the price per volume (4 numbers) is $\$ 18.00$; single issues, $\$ 5.00$. Special price for current issues to individual faculty members of supporting institutions and to individual members of the American Mathematical Society: $\$ 8.00$ per volume; single issues $\$ 2.50$. Back numbers are available.

Subscriptions, orders for back numbers, and changes of address should be sent to Pacific Journal of Mathematics, 103 Highland Boulevard, Berkeley 8, California.

Printed at Kokusai Bunken Insatsusha (International Academic Printing Co., Ltd.), No. 6 , 2-chome, Fujimi-cho, Chiyoda-ku, Tokyo, Japan.

\section{PUBLISHED BY PACIFIC JOURNAL OF MATHEMATICS, A NON-PROFIT CORPORATION}

The Supporting Institutions listed above contribute to the cost of publication of this Journal, but they are not owners or publishers and have no responsibility for its content or policies. 


\section{Pacific Journal of Mathematics}

\section{Vol. 13, No. $4 \quad$ June, 1963}

Dallas O. Banks, Bounds for eigenvalues and generalized convexity ........... 1031

Jerrold William Bebernes, A subfunction approach to a boundary value problem for

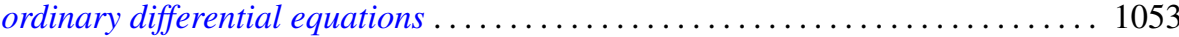

Woodrow Wilson Bledsoe and A. P. Morse, A topological measure construction . . . 1067

George Clements, Entropies of several sets of real valued functions . . . . . . . . . 1085

Sandra Barkdull Cleveland, Homomorphisms of non-commutative *-algebras . . . . . 1097

William John Andrew Culmer and William Ashton Harris, Convergent solutions of

ordinary linear homogeneous difference equations . . . . . . . . . . . . . . . 1111

Ralph DeMarr, Common fixed points for commuting contraction mappings . . . . . . 1139

James Robert Dorroh, Integral equations in normed abelian groups . . . . . . . . 1143

Adriano Mario Garsia, Entropy and singularity of infinite convolutions . . . . . . . 1159

J. J. Gergen, Francis G. Dressel and Wilbur Hallan Purcell, Jr., Convergence of extended Bernstein polynomials in the complex plane ................. 1171

Irving Leonard Glicksberg, A remark on analyticity of function algebras . . . . . . 1181

Charles John August Halberg, Jr., Semigroups of matrices defining linked operators

with different spectra ................................. 1187

Philip Hartman and Nelson Onuchic, On the asymptotic integration of ordinary

differential equations . . . . . . . . . . . . . . . . . . . . . . . . . . . . 1193

Isidore Heller, On a class of equivalent systems of linear inequalities . . . . . . . . . 1209

Joseph Hersch, The method of interior parallels applied to polygonal or multiply

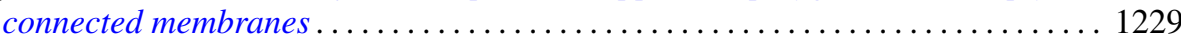

Hans F. Weinberger, An effectless cutting of a vibrating membrane . . . . . . . . . . 1239

Melvin F. Janowitz, Quantifiers and orthomodular lattices ....

Samuel Karlin and Albert Boris J. Novikoff, Generalized convex inequalities . .

Tilla Weinstein, Another conformal structure on immersed surfaces of negative

curvature.

Gregers Louis Krabbe, Spectral permanence of scalar operators

Shige Toshi Kuroda, Finite-dimensional perturbation and a representaion of

scattering operator.

Marvin David Marcus and Afton Herbert Cayford, Equality in certain

inequalities

Joseph Martin, A note on uncountably many disks .

Eugene Kay McLachlan, Extremal elements of the convex cone of semi-norms . . . . 1335

John W. Moon, An extension of Landau's theorem on tournaments . .

Louis Joel Mordell, On the integer solutions of $y(y+1)=x(x$

Kenneth Roy Mount, Some remarks on Fitting's invariants .....

Miroslav Novotný, Über Abbildungen von Mengen ............

Robert Dean Ryan, Conjugate functions in Orlicz spaces.

John Vincent Ryff, On the representation of doubly stochastic operators . . . . . . . . 1379

Donald Ray Sherbert, Banach algebras of Lipschitz functions .

James McLean Sloss, Reflection of biharmonic functions across analytic boundary

conditions with examples.

L. Bruce Treybig, Concerning homogeneity in totally ordered, connected topological space....

John Wermer, The space of real parts of a function algebra...

James Juei-Chin Yeh, Orthogonal developments of functionals and related theorems

in the Wiener space of functions of two variables......... 